\title{
Surveillance of Plasmodium falciparum pfcrt haplotypes in southwestern Uganda by high- resolution melt analysis
}

\author{
Kennedy Kassaza 1,2, Anna C. Long 3 , Jennifer M. McDaniels ${ }^{3}$, Mharlove Andre ${ }^{3}$, Wasswa Fredrickson², \\ Dan Nyehangane', Patrick Orikiriza', Darwin J. Operario', Joel Bazira², Juliet A. Mwanga-Amumpaire ${ }^{1,5}$, \\ Christopher C. Moore ${ }^{4}$, Jennifer L. Guler ${ }^{3,4^{*}}$ (ID and Yap Boum II ${ }^{1,2^{*}}$
}

\begin{abstract}
Background: Chloroquine (CQ) resistance is conferred by mutations in the Plasmodium falciparum CQ resistance transporter ( $p f c r t)$. Following CQ withdrawal for anti-malarial treatment, studies across malaria-endemic countries have shown a range of responses. In some areas, CQ sensitive parasites re-emerge, and in others, mutant haplotypes persist. Active surveillance of resistance mutations in clinical parasites is essential to inform treatment regimens; this effort requires fast, reliable, and cost-effective methods that work on a variety of sample types with reagents accessible in malaria-endemic countries.

Methods: Quantitative PCR followed by High-Resolution Melt (HRM) analysis was performed in a field setting to assess pfcrt mutations in two groups of clinical samples from Southwestern Uganda. Group 1 samples (119 in total) were collected in 2010 as predominantly Giemsa-stained slides; Group 2 samples (125 in total) were collected in 2015 as blood spots on filter paper. The Rotor-Gene Q instrument was utilized to assess the impact of different PCR-HRM reagent mixes and the detection of mixed haplotypes present in the clinical samples. Finally, the prevalence of the wild type (CVMNK) and resistant pfcrt haplotypes (CVIET and SVMNT) was evaluated in this understudied Southwestern region of Uganda.

Results: The sample source (i.e. Giemsa-stained slides or blood spots) and type of LCGreen-based reagent mixes did not impact the success of PCR-HRM. The detection limit of $10^{-5} \mathrm{ng}$ and the ability to identify mixed haplotypes as low as $10 \%$ was similar to other HRM platforms. The CVIET haplotype predominated in the clinical samples (66\%, 162/244); however, there was a large regional variation between the sample groups (94\% CVIET in Group 1 and $44 \%$ CVIET in Group 2).
\end{abstract}

Conclusions: The HRM-based method exhibits the flexibility required to conduct reliable assessment of resistance alleles from various sample types generated during the clinical management of malaria. Large regional variations in

\footnotetext{
*Correspondence: jlg5fw@virginia.edu; yap.boum@epicentre.msf.org

${ }^{\dagger}$ Kennedy Kassaza, Anna C. Long and Jennifer M. McDaniels contributed equally to this work

2 Department of Microbiology, Mbarara University of Science

and Technology, Mbarara, Uganda

${ }^{4}$ Division of Infectious Diseases and International Health, University

of Virginia, Charlottesville, VA 22904, USA

Full list of author information is available at the end of the article
}

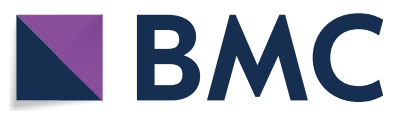

(c) The Author(s) 2021. This article is licensed under a Creative Commons Attribution 4.0 International License, which permits use, sharing, adaptation, distribution and reproduction in any medium or format, as long as you give appropriate credit to the original author(s) and the source, provide a link to the Creative Commons licence, and indicate if changes were made. The images or other third party material in this article are included in the article's Creative Commons licence, unless indicated otherwise in a credit line to the material. If material is not included in the article's Creative Commons licence and your intended use is not permitted by statutory regulation or exceeds the permitted use, you will need to obtain permission directly from the copyright holder. To view a copy of this licence, visit http://creativeco mmons.org/licenses/by/4.0/. The Creative Commons Public Domain Dedication waiver (http://creativecommons.org/publicdomain/ zero/1.0/) applies to the data made available in this article, unless otherwise stated in a credit line to the data. 
CQ resistance haplotypes across Southwestern Uganda emphasizes the need for continued local parasite genotype assessment to inform anti-malarial treatment policies.

Keywords: Uganda, Chloroquine, Plasmodium falciparum, Resistance, pfcrt, HRM

\section{Background}

In 2018, the World Health Organization reported over 228 million cases of malaria across the world and $5 \%$ of all cases are reported from Uganda [1]. The treatment of malaria is complicated on a global scale due to increased drug resistance to anti-malarials including chloroquine (CQ), sulfadoxine-pyrimethamine, mefloquine, and most recently, artemisinin [1]. CQ resistance is associated with mutations in the $P$. falciparum CQ resistance transporter $(p f c r t)$ gene, which encodes a transmembrane protein localized to the parasite digestive vacuole membrane [2]. Mutations in residues 72-76 of PfCRT contribute to altered efflux of CQ from the vacuole, which is the site of action for the drug [3]. The K76T mutation is a well-known marker of CQ resistance in Uganda [4]; this mutation may contribute to decreased sensitivity to lumefantrine [5]. While the normal haplotype across residues $72-76$ is CVMNK, the mutant haplotype CVIET confers a high level of resistance [6] and is the most common in Africa [7]. The mutant SVMNT haplotype that is most common in South American isolates [6, 8-10] has a lower level of resistance compared to the CVIET haplotype [11]. This haplotype has recently been detected in Africa and surveillance of SVMNT is important due to possible cross-resistance to amodiaquine $[12,13]$.

The withdrawal of CQ as a therapy for malaria has led to the almost complete re-emergence of CQ-sensitive parasite populations in Malawi [14], Kenya and Tanzania $[15,16]$, and Northern regions of Uganda [5]. In other regions of the world, CQ resistant parasites persist decades after CQ cessation [17-19]. In general, a multitude of studies across Africa have observed a wide range in the proportion of CQ resistant parasites [20-28], which emphasizes the need for continued surveillance of resistance markers.

In this report, a PCR-based high-resolution melt (HRM) assay was used to screen 244 clinical samples from Southwestern Uganda for pfcrt mutant haplotypes. HRM is moderate throughput and yields few false positives $[29,30]$, exhibits high sensitivity and specificity in a variety of organisms [31-33], and can be employed inexpensively to screen samples prior to sequencing [30]. A previous highly accurate HRM assay of $p f c r t$ haplotypes [34] was adopted for use on a distinct HRM instrument, evaluated for its performance with different reagents and sample types, and assessed for its ability to detect mixed alleles. Overall, both
CVMNK and CVIET haplotypes were detected with high confidence in Southwestern Ugandan samples but resistance prevalence varied depending on location.

\section{Methods \\ Study area and clinical isolates}

Southwestern Uganda is mesoendemic for malaria. The highest transmission rates occur after the rainy season (September-January and March-May) [35]. Clinical samples used in this study were originally collected during previous cross-sectional studies in Southwestern Uganda. The studies were performed at Epicentre Mbarara Research Centre, a research arm of Médecins sans Frontières, and Mbarara University of Science and Technology [36, 37].

Group 1 samples were collected while conducting household surveys of asymptomatic children $<5$ years old from the districts of Ibanda, Isingiro, Kiruhura, and Mbarara in 2010 [32, 37-39] (Fig. 1a). Sampling was performed across low and high transmission seasons [37, 38]. Group 2 samples were collected from symptomatic patients in a peripheral health center in the district of Kasese across both low and high transmission seasons of 2015 [36] (Fig. 1a). All samples included in this study were positive for malaria, as confirmed by rapid diagnostic tests (RDT) and microscopy.

\section{Clinical sample preparation}

Genomic DNA was extracted from Giemsa-stained slides, frozen blood pellets, and blood spots (summarized in Fig. 1b). Of the 119 total Group 1 samples, 117 DNA samples were from Giemsa-stained thick blood smears (stored at ambient temperature for 5 years before DNA purification) and two samples from frozen blood pellets (total volume of $100 \mu \mathrm{l}$ ) as previously reported [32]. Following extraction using the QIAamp DNA Mini Kit (Qiagen Inc., Germantown, Maryland, USA), these samples were also previously verified positive for $P$. falciparum using a species-specific HRM assay [32]. For Group 2, a total of 125 samples were extracted from filter paper blood spots using the QIAamp DNA Mini Kit (Qiagen Inc., Germantown, Maryland, USA). A subset of these samples were verified positive for $P$. falciparum as above prior to proceeding with haplotype analysis [32]. 


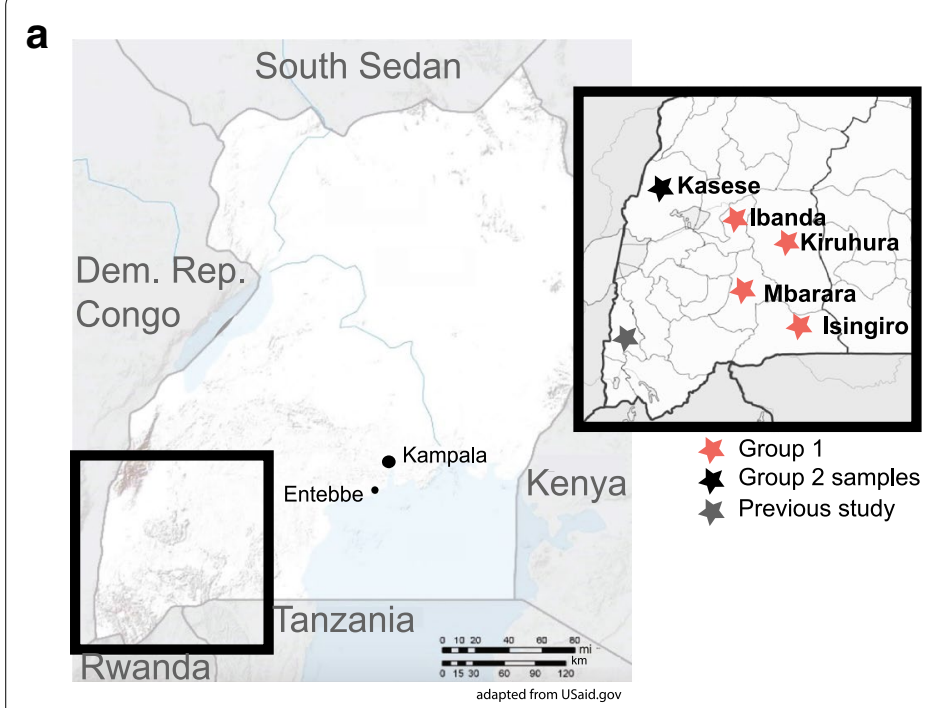

b

Giemsa stained thick blood smears (Group 1, 128 samples) Blood pellets (Group 1, 2 samples) Blood spots (Group 2, 128 samples)
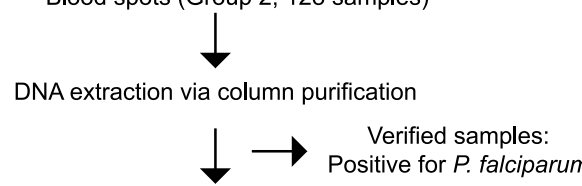

DNA amplification via qPCR on Rotor-Gene $Q$

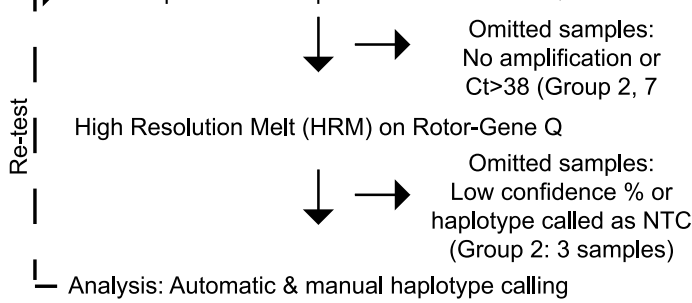

Fig. 1 Clinical sample collection sites in Uganda and overview of methods for detection of pfcrt haplotypes. a Samples were collected in Southwest Uganda in the districts of Ibanda, Isingiro, Kiruhura, and Mbarara in 2010 (red stars) and the district of Kasese in 2015 (black star). Kunungu (grey star) was evaluated in previous studies $[28,40]$ and is used as a regional and temporal comparator. $\mathbf{b}$ Work flow of DNA isolation methods extracted from various sources followed by High-Resolution Melt analysis

\section{Reference DNA and gene loci}

Plasmodium falciparum genomic DNA controls were included in each run to validate assay performance and assign genotypes to the clinical samples. Genomic DNA from three $P$. falciparum reference strains with known pfcrt haplotypes (GenBank accession number NC_004328.2:458,600-461,695, gene ID: 2,655,199) were obtained from BEI resources (NIAID, NIH, Manassas, VA, USA): P. falciparum HB3 (wild type CVMNK haplotype, MRA-155G, contributed by Thomas E. Wellems), 7 G8 (mutant haplotype $\underline{S} V M N \underline{T}$, MRA-152G, contributed by David Walliker), 7C424 (mutant haplotype CVIET, MRA-175G, contributed by Thomas E. Wellems). To ensure accurate genotyping, each control line was sequenced and confirmed for correct $p f c r t$ mutations (Additional file 1: Fig. S1). Control samples provided reproducible melt curves which were used to determine the correct genotype of clinical samples with confidence.

\section{Quantitative PCR assays and cycling}

The Rotor-Gene Q real-time PCR cycler (Qiagen Inc., Germantown, Maryland, USA) with a 72-well rotor was used for both PCR and HRM steps. Primers and probe with modified C3 spacer were purchased from Integrated DNA Technologies (IDT, Inc., Coralville, Iowa, USA). The primers and probe used were as follows [34]: Forward primer: $5^{\prime}$-GTAAAACGACGGCCAGTTTCTTGT CTTGGTAAATGTGCTCA-3', Reverse primer: 3'-CAG GAAACAGCTATGACCGGATGTTACAAAACTATA GTTACCAAT-5', HRM probe: 5'-GTGTATGTGTAA
TGAATAAAATTTTTG(3SpC3)-3'. Asymmetric PCRs were performed with the reverse primer in 10-fold excess to promote the accumulation of single-stranded DNA for probe binding [41]. The unlabelled HRM probe detected mutations across the 72-76 codon region. The C3 spacer on the end of the probe was necessary to prevent extension of the probe during PCR amplification. During the HRM steps, the probe disassociates from the mutant and wild type template DNA at distinct melting temperatures [34].

Either LightScanner Master mix (BioFire ${ }^{\mathrm{TM}}$ Defense, Salt Lake City, Utah, USA) or HotstarTaq Master mix (Qiagen Inc., Germantown, Maryland, USA) paired with $10 \times$ LCGreen Melting Dye (BioFire $^{\mathrm{TM}}$ Defense, Salt Lake City, Utah, USA) was used for PCR amplification and HRM analysis. Although the Eva-Green-based Type-it HRM PCR kit (Qiagen Inc., Germantown, Maryland, USA) was recommended for use with the Rotor-Gene Q, The LightScanner and HotStarTaq mixes were selected based on their availability for purchase in Uganda.

Both mixes use LCGreen, which is a double strand DNA dye that is specifically designed for use during HRM since it facilitates the detection of heteroduplexes. The Lightscanner mix already has LCGreen included, while it must be added to the HotStar mix. In addition, the two mixes have slightly different levels of magnesium chloride, an important cofactor for the polymerase (Lighscanner: $2 \mathrm{mM}$, Hotstar: $3 \mathrm{mM}$ ) and employ different methods of preventing polymerase action prior to the start of PCR; this latter difference impacts the length of 
the polymerase activation step at the beginning of cycling (Lighscanner: antibody-based hot start requires $2 \mathrm{~min}$, HotStar: inactive polymerase requires $15 \mathrm{~min}$ ).

For LightScanner assays (Group 1 samples), the following components were added per $20 \mu \mathrm{L}$ reaction: $8 \mu \mathrm{L}$ of 2.5x LightScanner master mix, forward primer $(1 \mu \mathrm{M}$ final), reverse primer $(10 \mu \mathrm{M}$ final), probe $(8 \mu \mathrm{M}$ final), and $3 \mu \mathrm{L}$ of sample DNA, reference DNA (1 ng) or nuclease-free water (no template control, NTC). For HotStarTaq assays (Group 2 samples), the following components were added per $20 \mu \mathrm{L}$ reaction: $10 \mu \mathrm{L}$ of $2 x$ HotStarTaq master mix, $1 \mu \mathrm{L}$ of $10 \times \mathrm{LC}$ Green, forward primer $(1 \mu \mathrm{M}$ final), reverse primer $(10 \mu \mathrm{M}$ final), probe $(8 \mu \mathrm{M}$ final), and $3 \mu \mathrm{L}$ of sample DNA, reference DNA (1 ng) or NTC.

PCR cycling conditions were performed with an initial $2 \mathrm{~min}$ hold for LightScanner assays $(15 \mathrm{~min}$ hold for HotStarTaq assays) at $95^{\circ} \mathrm{C}$ followed by 50 cycles of $90^{\circ} \mathrm{C}$ for $30 \mathrm{~s}, 60^{\circ} \mathrm{C}$ for LightScanner assays $\left(56^{\circ} \mathrm{C}\right.$ for HotStarTaq assays) for $30 \mathrm{~s}$, and $72^{\circ} \mathrm{C}$ for $30 \mathrm{~s}$. Fluorescence data was acquired during the $72{ }^{\circ} \mathrm{C}$ step. The last cycle was followed by a $98^{\circ} \mathrm{C}$ hold for $2 \mathrm{~min}$ and a $40^{\circ} \mathrm{C}$ hold for $2 \mathrm{~min}$ before continuing to the HRM analysis (see Sect. 2.5). Fluorescence intensities of clinical samples, genomic DNA controls, and NTC were recorded in realtime throughout amplification cycles, which was used to determine the cycle threshold values for each assay (Fig. 2a).

\section{High-resolution melt (HRM) parameters and analysis}

Following PCR, the melting curve programme consisted of the following steps: a $90 \mathrm{~s}$ step of pre-melt conditioning at $50^{\circ} \mathrm{C}$ followed by an increase in temperature from 50 to $90^{\circ} \mathrm{C}$ in $0.2^{\circ} \mathrm{C}$ increments every $2 \mathrm{~s}$. The change in fluorescence was measured at each $0.2^{\circ} \mathrm{C}$ increment. Manual gain optimization settings were as follows: set for $60^{\circ} \mathrm{C}$, HRM gain optimization was turned on at tube position 1 , and set to select the highest fluorescence less than 70 . Gain was set to a minimum and maximum reading of $1 \mathrm{Fl}$ and $3 \mathrm{Fl}$, and a minimum and maximum gain of -10 and 10. Rotor-Gene Q Series Software version 2.2.1, Build 49 (Qiagen Inc., Germantown, Maryland, USA) was used for analysis of PCR and HRM data. Melt analysis curves were normalized between 51 and $71^{\circ} \mathrm{C}$ (manually set) to capture the melting of the unlabelled probe from the full template (Fig. 2b). Narrower normalization regions were assessed and did not change the outcome of the analysis (Additional file 1: Fig. S2).

The haplotypes of clinical samples were automatically called by the Rotor-Gene Q software compared to the known genomic DNA controls, which produced reproducible HRM profiles. The difference curve (normalized to the NTC) was used to compare the melting profile of the probe/template duplexes (Fig. 2c). The confidence
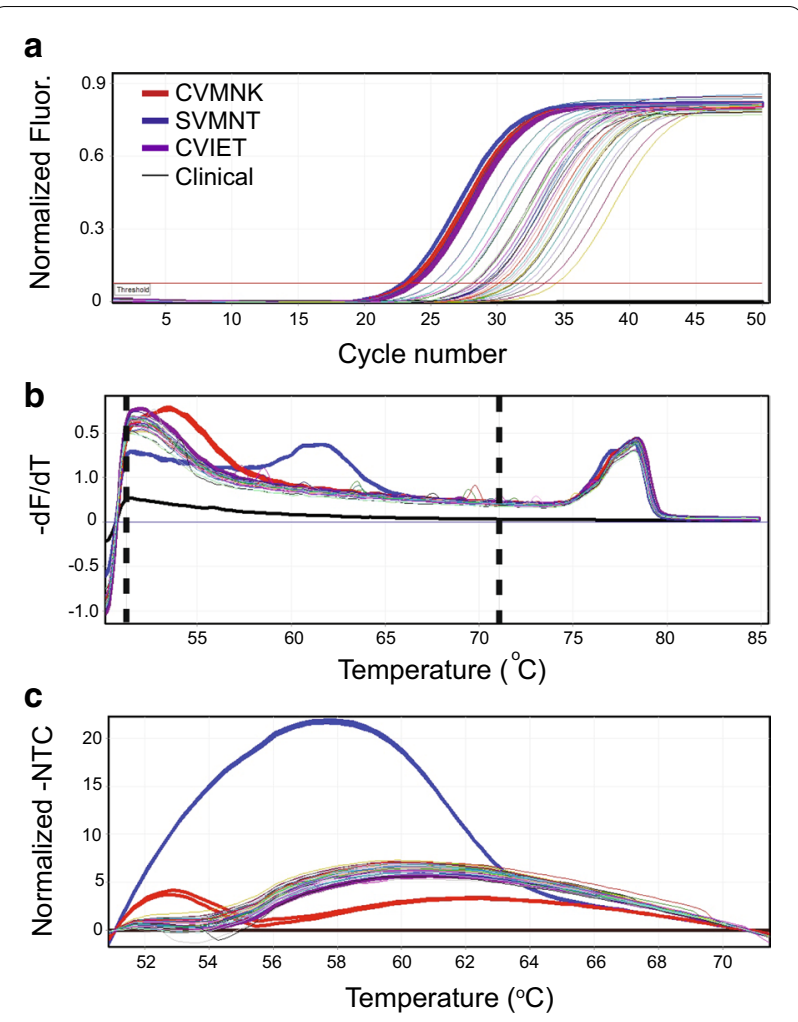

Fig. 2 Summary of quantitative PCR and High-Resolution Melt parameters and analysis. Representative graphs of quantitative PCR and High-Resolution Melt analysis of clinical samples (thin coloured lines) and control samples (bold lines, blue: CVMNK wild type, HB3 parasite line; red: mutant SVMNT haplotype, 7 G8 parasite line; purple: mutant CVIET haplotype, 7C424 parasite line). All analysis was performed with Rotor-Gene Q software and colours and line thickness were modified with TeeChart. a LCGreen fluorescence-based real time detection of DNA amplification of clinical samples and genomic DNA controls. Horizontal red line denotes the Ct threshold, which was determined for each assay. b A derivative plot displaying the melt analysis curve highlighting probe dissociation between normalization regions (denoted by dashed lines at $51^{\circ} \mathrm{C}$ and $71^{\circ} \mathrm{C}$ ). The change in fluorescence was recorded in $0.2{ }^{\circ} \mathrm{C}$ increments every $2 \mathrm{~s}$. c Difference curve normalized to the no template control (NTC). The shape of the curve between the normalization region (see panel B) dictates the automatic genotype call

percentage threshold was set to $20 \%$ to allow for low confidence calls to be recognized by the software. Confidence percentages were used as an integrity check (per the manufacturer's instructions). Values above the threshold were subject to automatic calls predicted by the software. Values below the threshold were called as a "variation" and followed by a re-test (see Fig. 1b). If the amplitude or shape of the sample curve was different than the controls, the genotype was also determined by the programme to be a "variation". For increased accuracy, each automatic call was manually inspected through visual comparison 
of the normalized difference curve (Fig. 2c). If a mistake in the genotype call was plainly discernible due to a visual discrepancy in the automatic genotype call and the difference curve, then a "manual call" was made (indicated in Additional file 1: Table S1). XY plots were generated using GraphPad Prism 7.0 (GraphPad Prism, La Jolla, CA).

\section{Data quality control}

The combination of the $\mathrm{Ct}$ value, confidence percentage, and manual inspection allowed for heightened confidence in haplotype calling. Samples were re-tested if: (1) the $\mathrm{Ct}$ value was greater than 38 (equivalent to $\sim 10^{-5} \mathrm{ng}$ of parasite DNA), (2) the sample failed to amplify on the first run, or (3) an abnormal genotype needed to be verified. Of note, the majority of re-test samples gave consistent calls (Group 1: 12/14 ( 86\%) and Group 2: 4/4 $(100 \%)$. Samples were omitted in three scenarios: (1) there was no amplification of the DNA and, therefore, no $\mathrm{Ct}$ value, (2) the $\mathrm{Ct}$ value of the samples were repeatedly above the 38 cycle cutoff, and (3) the genotype call was listed as NTC (no template control) (Fig. 1b). NTC melt curves were flat, displayed no $\mathrm{Ct}$ value, and did not resemble any of the positive controls.

\section{Results}

Various sample types and amplification reagents yield high confidence pfcrt haplotype calls

DNA from 244 samples was PCR-amplified and analysed using HRM on the Rotor-Gene Q instrument. In general, the range of $\mathrm{Ct}$ values for the quantitative PCR step was similar between the two groups (Fig. 3a and b). Mean $\mathrm{Ct}$ values of the Giemsa-stained slides and blood pellets (Group 1), and blood spot (Group 2) samples were 28.1, 35, and 31 cycles, respectively (Additional file 1: Table S1). Mean Ct values from CVMNK, CVIET and SVMNK haplotypes called in the two groups also displayed a similar range (Fig. $3 \mathrm{a}$ and $\mathrm{b}$ ) and mean (mean $\mathrm{Ct}$ value of Group 1 CVMNK: 30.2; CVIET: 28.1 and Group 2 CVMNK: 31.6; CVIET: 30.2; SVMNT: 26.8 cycles). Two PCR-HRM reagent mixes were used over the course of the study due to differences in their accessibility: for Group 1 samples, LightScanner Master mix was used, which includes LC-Green dye;for Group 2 samples, HotstarTaq Master mix with added LC-Green dye was used. Similar to the analysis of sample type and haplotype, no notable differences were detected between the two different mixes in Ct value range (Fig. $3 a$ and $b$ ) and mean (mean Ct value of Group 1: 28.2 and Group 2: 31.1 cycles).

Sample material was not normalized prior to amplification because DNA purified from clinical samples contains both human and parasite genomes. However, through the use of parasite DNA controls of known concentration (HB3, 7G8, 7C424), the clinical parasite DNA concentration range was estimated to be between $\sim 1 \mathrm{ng}$ and $10^{-5}$ ng per reaction. The lowest DNA concentration used in this study and the lowest DNA concentration detected by HRM were estimated to be between $10^{-4}$ and $10^{-5}$ ng per reaction. This limit of detection for HRM is consistent with previous publications [34, 42, 43].

Following HRM steps, the $p f c r t$ haplotype was automatically called by the Rotor-Gene software and inspected manually for accuracy (see Methods for details). Overall, mean confidence percentages across the different groups were $>89 \%$ (Table 1; Fig. 3a and b). Further supporting

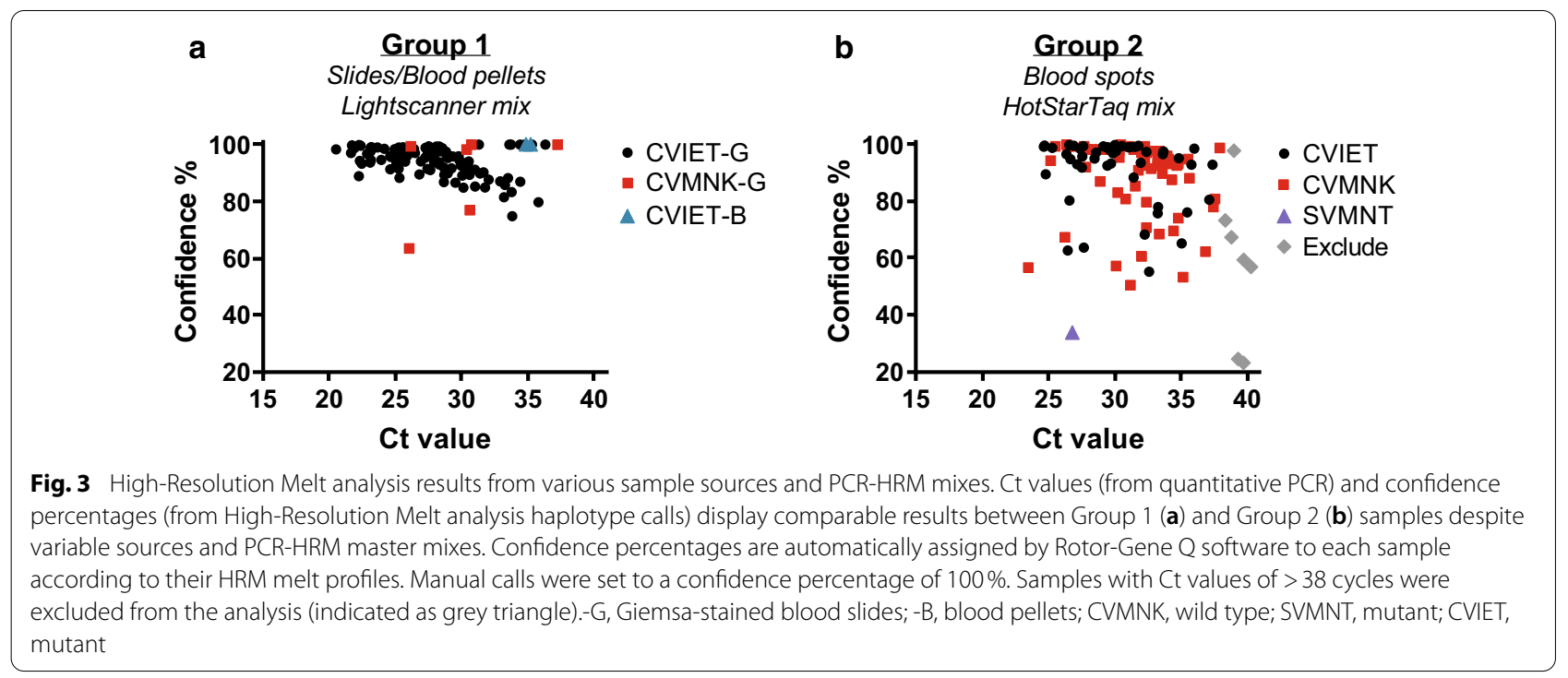


the reliability of the automatic haplotype calls, there was an inverse correlation between $\mathrm{Ct}$ value and confidence percentage ( $p$ value of $2.243 \mathrm{e}-9$, Additional file 1: Fig. S3). The average confidence percentage produced by automatic calls was $>90 \%$ for all sample types and haplotypes (Table 1). Manual calls, which were made when a visual discrepancy was identified on the difference curve, represented only $9.2 \%(11 / 244)$ of calls and were confined to Group 1 samples (Additional file 1: Table S1). Additionally, a larger percentage of samples from this group had to be re-tested due to high Ct values, NTC, or variant calls $(10.9 \%$ or $13 / 119$ of Group 1 samples versus $3.2 \%$ or $4 / 125$ of Group 2 samples solely derived from blood spots, Additional file 1: Table S1). These Group 1 sample characteristics may be due to the slightly lower quality of DNA of the samples (derived from Giemsastained slides and collected 5 years earlier).

\section{The mutant CVIET haplotype is common in southwestern Uganda}

Overall, $66 \%$ of the samples tested were called as the CVIET haplotype (162/244). The mutant CVIET haplotype was detected in the majority of the Group 1 samples $(94.1 \% ; 112 / 119$ samples, Table 1$)$. Only $5 \%(6 / 119)$ showed the wild type, CVMNK haplotype. However, the CVIET haplotype was less prominent in the Group 2 samples (43.8\%; 50/114, Table 1); more than half of samples were called as the CVMNK haplotype (52.6\%;
60/114). A single Group 2 sample displayed the mutant SVMNT haplotype $(0.9 \% ; 1 / 114)$. However, due to a low confidence percentage $(\sim 34 \%$, Fig. $3 b$, Additional file 1 : Table S1), classification of this sample was likely not accurate. Overall, only 4 clinical samples were called as variations (1/119 and 3/114 from Group 1 and 2 samples, respectively, Additional file 1: Table S1). Although the Ct value of these samples were in range of the other samples ( 30-37 cycles), they exhibited an unknown melting profile that was not identified as CVMNK, SVMNK, or CVIET. These variants could, therefore, represent novel CQ mutations, alternative haplotypes (non-CVMNK/ SVMNT/CVIET), or mixed haplotypes.

\section{The identification of mixed haplotypes requires manual inspection}

Other major haplotypes are not likely to be present in the clinical samples; wild type CVMNK and mutant CVIET haplotypes together covered $99.2 \%$ of Group 1 samples and $96.5 \%$ of Group 2 samples (Table 1). To investigate the ability of the Rotor-Gene Q instrument to call mixed haplotypes, control samples were tested at various ratios of 90:10 (SVMNT:CVMNK), 50:50 (SVMNT:CVIET), and 30:30:30 (CVMNK:SVMNT:CVIET). The sample with an equal proportion of two haplotypes (50:50) exhibited a prominent shoulder at a lower melting temperature (Fig. 4a). This shoulder was predicted to be due to heteroduplex formation (a mixture of both genotypes

Table 1 Summary of High-Resolution Melt assay results and important metrics

\begin{tabular}{|c|c|c|c|c|c|c|}
\hline Group & No. samples ${ }^{a}$ & pfert haplo & & No. called (\%) & Mean confidence $\%^{d}$ & $\begin{array}{l}\text { Mean Ct } \\
\text { Value }\end{array}$ \\
\hline \multirow[t]{5}{*}{$1^{b}$} & 119 & CVMNK & Wild type & $\begin{array}{l}6(5.0) \\
M C: 2\end{array}$ & 84.6 & $\begin{array}{l}30.2 \\
M C: 34.0\end{array}$ \\
\hline & & SVMNI & Mutant & $0(0 \%)$ & N/A & $\mathrm{N} / \mathrm{A}$ \\
\hline & & CVIET & Mutant & $\begin{array}{l}112(94.1) \\
M C: 11\end{array}$ & 93.8 & $\begin{array}{l}28.1 \\
M C: 34.4\end{array}$ \\
\hline & & Unknown & Variation & $1(0.8)$ & n.d. & 30.1 \\
\hline & & & & & Overall Mean: $93.5 \%$ & Overall Mean: 28.2 \\
\hline \multirow[t]{5}{*}{$2^{c}$} & 114 & CVMNK & Wild type & $60(52.6)$ & 88.2 & 31.6 \\
\hline & & $\underline{\text { SVMNT }}$ & Mutant & $1(0.9 \%)$ & $33.6^{\mathrm{e}}$ & $* 26.8$ \\
\hline & & CVIET & Mutant & $50(43.9 \%)$ & 91.5 & 30.2 \\
\hline & & Unknown & Variation & $3(2.6 \%)$ & n.d. & 35.1 \\
\hline & & & & & Overall Mean: $89.7 \%$ & Overall Mean: 31.1 \\
\hline \multicolumn{7}{|c|}{ a Analyzed samples only include those with a $\mathrm{Ct}$ value $<38$} \\
\hline \multicolumn{7}{|c|}{ b DNA samples were purified from predominantly Giemsa-stained slides } \\
\hline \multicolumn{7}{|c|}{${ }^{c}$ DNA samples were purified from blood spots on filter paper } \\
\hline \multicolumn{7}{|c|}{ d Mean confidence $\%$ is assigned by software when automatic calls were made } \\
\hline \multicolumn{7}{|c|}{ e Denotes the exact value since an average could not be calculated; omitted from total average calculation } \\
\hline \multicolumn{7}{|c|}{ Underline denotes amino acid changes from the wild type CVMNK haplotype } \\
\hline \multicolumn{7}{|c|}{$\begin{array}{l}\text { MC Manual Calls, CVMNK Cys-Val-Met-Asn-Lys, SVMNT Ser-Val-Met-Asn-Thr, CVIET Cys-Val-Ile-Glu-Thr, N/A not applicable, n.d. not determined (a confidence value could } \\
\text { not be assigned for these clinical samples due to their unknown melting profile) }\end{array}$} \\
\hline
\end{tabular}



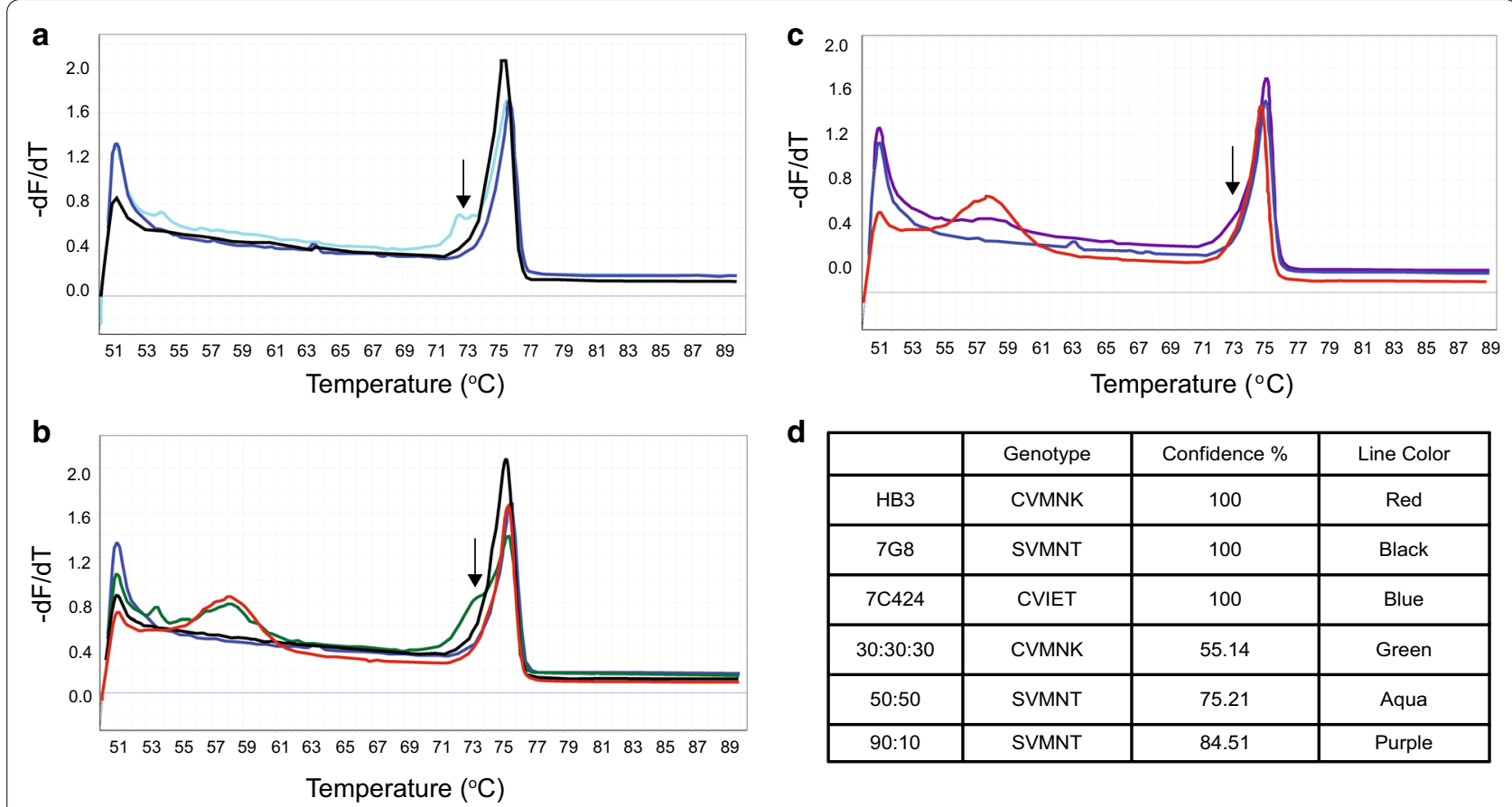

\begin{tabular}{|c|c|c|c|}
\hline & Genotype & Confidence \% & Line Color \\
\hline HB3 & CVMNK & 100 & Red \\
\hline $7 \mathrm{G} 8$ & SVMNT & 100 & Black \\
\hline $7 C 424$ & CVIET & 100 & Blue \\
\hline 30:30:30 & CVMNK & 55.14 & Green \\
\hline $50: 50$ & SVMNT & 75.21 & Aqua \\
\hline $90: 10$ & SVMNT & 84.51 & Purple \\
\hline
\end{tabular}

Fig. 4 High-Resolution Melt analysis of mixed pfcrt haplotypes using the Rotor-Gene Q instrument. Derivative plots displaying the melt analysis curve for a 50:50 haplotype mixture of reference genomic DNA (a, SVMNT:CVIET), 30:30:30 mixture (b, CVMNK:SVMNT:CVIET), and 90:10 mixture (c, SVMNT:CVMNK). The heteroduplex 'shoulder' (arrow) is due to the formation and melting of a heteroduplex of both full length amplicon sequences. d Summary table of genotype, confidence \% called by Rotor-Gene $Q$, and corresponding line colour

present) and was less prominent in non-equal mixtures (30:30:30 and 90:10, Fig. 4b and c). Notably, the RotorGene Q software did not have the capability to automatically call the mixed haplotypes. As predicted, it called the predominant genotype with lower confidence (Fig. 4d). Given these findings, all samples were manually reviewed, including those with low confidence levels and variation calls; however, no samples exhibited the characteristic heteroduplex shoulder. Thus, mixed haplotypes were not likely the explanation for the variation calls. Using the heteroduplex shoulder, it was possible to manually identify mixtures of down to $10 \%$ (Fig. 4c), as seen with other HRM platforms [42, 43]; analysis on the Rotor-Gene Q instrument was unable to reach a $1 \%$ detection limit as reported with mutant allele amplification bias (MAAB) on a LightScanner-32 instrument [34].

\section{Discussion}

Molecular genotyping studies have predominantly used gene-specific PCR followed by sequencing to identify resistance conferring mutations [26, 27, 44]. Other approaches such as ligase detection reaction-fluorescent microsphere assay $[28,40,45]$ and the quantitative PCRbased malariaTAC [46] facilitate higher sample throughput and the parallel assessment of multiple resistance alleles. Although lower throughput than these methods,
HRM-based assays allow for fast, reliable, and cost-effective haplotype analysis that is independent of sequencing and fluorescent probes [29, 30, 32, 34, 47]. Therefore, similar to SNP-loop mediated isothermal amplification (LAMP, [48-50], this method is amenable for surveillance efforts in settings in which malaria is endemic.

Importantly, the current studies show that HRM-based assessments of resistance alleles can be directly adopted for different instruments (i.e. BioFire Diagnostic's Lightscanner as in Daniels et al. versus Qiagen's Rotor-Gene $\mathrm{Q}$ used here). The flexibility of this method is emphasized by the high confidence data yielded from a variety of sample types and PCR-HRM reagents (Fig. 3). Giemsa-stained slides and blood spots are important sample sources that are collected during surveillance studies and are often archived for long periods of time. Using control samples, it is possible to detect mixed genotypes using the Rotor-Gene platform (Fig. 4); however, since the automatic genotype calls in the mixed samples had reduced confidence percentages, further evaluation would be required to investigate the exact genotypes present. The absence of mixed haplotypes in the clinical samples may be due to (1) the mesoendemic nature of infections in this region of Uganda, or (2) the possibility that minor alleles at this locus are below the HRM limit of detection ( $10 \%$ in this study). Due to the chance of 
missing minor resistance genotypes, this methodology may be better suited for surveillance (as conducted here) over 'point of care' assessments to determine anti-malarial treatment choice.

With the discovery of artemisinin resistance [51-53], the catalog of effective anti-malarials is dwindling. In response to growing resistance, there is a need to reevaluate historically effective treatments like CQ. Recent studies have assessed the response of parasite populations to CQ drug cessation in African countries [6, 8, 20$22,25-27,44,54]$, but there has been limited research conducted in Southwestern Uganda. Resistance patterns in Tororo, located in Eastern Uganda, have been the most thoroughly documented [20, 40, 45, 55]; recent studies have also included few districts in Southwestern Uganda (i.e. Kanumgu and Kabale [28, 40]).

The prevalence of $\mathrm{CQ}$ resistance haplotypes was assessed in parasite populations from multiple sites across Southwestern Uganda (Ibanda, Isingiro, Kiruhura, and Mbarara collected in 2010, and Kasese collected in 2015). Dominance of the mutant CVIET haplotype in the samples, and lack of the mutant SVMNT haplotype (Table 1), is consistent with what has been observed in other areas of Uganda and throughout sub-Saharan Africa during a similar time frame [5, 8, 20, 21, 26, 27, $40,44,54]$. Additionally, the prevalence of CVIET in Group 2 samples ( $45 \%$, from Kasese, Table 1$)$ is consistent with previous findings in the region $(\sim 50 \%$, from Kanungu in 2016, [28], see Fig. 1A for location comparisons). However, the high numbers of the mutant CVIET haplotype in Group 1 samples ( 95\%, from Ibanda, Isingiro, Kiruhura, and Mbarara, Table 1) is well above what was previously measured in the region around a similar time period ( $<5 \%$, from Kanungu in 2012, [40]). Despite limitations in the ability to assess temporal changes in CQ resistance levels across these regions (due to the collection of samples at two different time points, from different districts, and sampling methods), these studies illustrate that the variation in CQ resistance levels observed elsewhere also exists in locations across Southwestern Uganda. This finding emphasizes the need for continued regional assessments of resistant parasites profiles, using methods such as PCR-HRM, in order to inform any future use of CQ.

As an additional limitation, HRM-based methods cannot identify novel haplotypes because it measures the melting of a probe with a defined sequence from a homologous template. As mentioned above, there are not likely to be minor haplotypes in the study samples. Despite this result, it is possible that other minor resistance haplotypes have moved into the area (i.e. CVIEK, which has been detected in Sudan in 2000 [6] and in Nigeria in 2015 [56]). However, since the current study do not assess this haplotype, further investigations would be needed to explore this possibility in Uganda.

\section{Conclusions}

In conclusion, HRM-based methods exhibit the flexibility required to conduct reliable assessment of resistance alleles from various sample types that may be generated during clinical management of malaria. Furthermore, regional variation in mutant pfcrt haplotypes across Southwestern Uganda is observed; this result emphasizes the need to continue local assessments of parasite genotypes to inform anti-malarial treatment policies.

\section{Supplementary Information}

The online version contains supplementary material available at https://doi. org/10.1186/s12936-021-03657-7.

Additional file 1: Table S1. Summary of HighResolution Melt analysis on clinical samples. Figure S1. Targeted sequencingconfirms pfcrt haplotypes in control Plasmodium genomes. Figure S2. Change in normalization boundaries does notimpact automatic haplotype calling. Figure S3. Quantitative PCR Ct values are inverselyproportional to HRM confidence percentages.

\section{Abbreviations}

ACT: Artemisinin-based combination therapy; Ct: Cycle threshold; CQ: Chloroquine; HRM: High-resolution melt; MC: Manual calls; NTC: No template control; PfCRT: Plasmodium falciparum chloroquine resistance transporter; SW: Southwest.

\section{Acknowledgements}

We are grateful to individuals working and studying at Mbarara University of Science and Technology and the Epicentre Mbarara Research Centre for their hospitality and collaboration. We thank Ali Guler, Ph.D. for guidance on data presentation.

\section{Authors' contributions}

Conceived and designed the experiments: KK CCM JLG YB. Secured access to clinical samples: KK DN PO JB JAM YB. Performed the experiments: KK ACL JMM MA WF DJO JLG. Analysed the data: ACL JMM JLG. Contributed reagents/ materials/analysis tools: JAM CCM JLG YB. Wrote the manuscript: ACL JMM JLG. All authors read and approved the final manuscript.

\section{Funding}

This work was supported by NIH funded Minority Health and Health Disparities International Research Training Grant (JMM and MA, T37 MD008659), the University of Virginia Center for Global Health (ACL and CCM), the University of Virginia Henry Rose Carter Award (CCM), institutional startup funds (JLG), and the Uganda Research Student Support Fund (URSSF for KK and WF).

\section{Availability of data and materials}

The datasets used and/or analysed during the current study are available from the corresponding author on reasonable request.

\section{Ethics approval and consent to participate}

The samples were collected under previously approved studies [36, 37] and protocols were further approved by the institutional review boards of the Mbarara University of Science and Technology and Uganda National Council for Science and Technology.

Consent for publication

Not applicable. 


\section{Competing interests}

The authors declare that they have no competing interests.

\section{Author details}

${ }^{1}$ Epicentre Mbarara Research Centre, Mbarara, Uganda. ${ }^{2}$ Department of Microbiology, Mbarara University of Science and Technology, Mbarara, Uganda. ${ }^{3}$ Department of Biology, University of Virginia, Box 400328 , 22904 Charlottesville, VA, USA. ${ }^{4}$ Division of Infectious Diseases and International Health, University of Virginia, Charlottesville, VA 22904, USA. ${ }^{5}$ Department of Pediatrics and Child Health, Mbarara University of Science and Technology, Mbarara, Uganda.

Received: 21 November 2020 Accepted: 18 February 2021

Published online: 25 February 2021

\section{References}

1. WHO Group. World Malaria Report 2019. Geneva: Organization WH; 2019.

2. Djimdé A, Doumbo OK, Cortese JF, Kayentao K, Doumbo S, Diourté Y, et al. A molecular marker for chloroquine-resistant falciparum malaria. N Engl J Med. 2001;344:257-63.

3. Ecker A, Lehane AM, Clain J, Fidock DA. PfCRT and its role in antimalarial drug resistance. Trends Parasitol. 2012;28:504-14.

4. Dorsey G, Kamya MR, Singh A, Rosenthal PJ. Polymorphisms in the Plasmodium falciparum pfcrt and pfmdr-1 genes and clinical response to chloroquine in Kampala, Uganda. J Infect Dis. 2001;183:1417-20.

5. Balikagala B, Sakurai-Yatsushiro M, Tachibana S-I, Ikeda M, Yamauchi $M$, Katuro OT, et al. Recovery and stable persistence of chloroquine sensitivity in Plasmodium falciparum parasites after its discontinued use in Northern Uganda. Malar J. 2020;19:76.

6. Fidock DA, Nomura T, Talley AK, Cooper RA, Dzekunov SM, Ferdig MT, et al. Mutations in the P. falciparum digestive vacuole transmembrane protein PfCRT and evidence for their role in chloroquine resistance. Mol Cell. 2000;6:861-71.

7. Khalil IF, Alifrangis M, Tarimo DS, Staalsø T, Satti GMH, Theander TG, et al. The roles of the pfcrt 76T and pfmdr1 86Y mutations, immunity and the initial level of parasitaemia, in predicting the outcome of chloroquine treatment in two areas with different transmission intensities. Ann Trop Med Parasitol. 2005:99:441-8.

8. Keen J, Farcas GA, Zhong K, Yohanna S, Dunne MW, Kain KC. Real-time PCR assay for rapid detection and analysis of PfCRT haplotypes of chloroquine-resistant Plasmodium falciparum isolates from India. J Clin Microbiol. 2007:45:2889-93.

9. Mehlotra RK, Fujioka H, Roepe PD, Janneh O, Ursos LM, Jacobs-Lorena V, et al. Evolution of a unique Plasmodium falciparum chloroquine-resistance phenotype in association with pfcrt polymorphism in Papua New Guinea and South America. Proc Natl Acad Sci USA. 2001:98:12689-94.

10. Wellems TE, Plowe CV. Chloroquine-resistant malaria. J Infect Dis. 2001;184:770-6.

11. Sa JM, Twu O. Protecting the malaria drug arsenal: halting the rise and spread of amodiaquine resistance by monitoring the PFCRT SVMNT type. Malar J. 2010;9:374.

12. Alifrangis $M$, Dalgaard MB, Lusingu JP, Vestergaard LS, Staalsoe T, Jensen ATR, et al. Occurrence of the Southeast Asian/South American SVMNT haplotype of the chloroquine-resistance transporter gene in Plasmodium falciparum in Tanzania. J Infect Dis. 2006;193:1738-41.

13. Gama BE, Pereira-Carvalho GA, Lutucuta Kosi FJ, Almeida de Oliveira NK, Fortes F, Rosenthal PJ, et al. Plasmodium falciparum isolates from Angola show the StctVMNT haplotype in the pfcrt gene. Malar J. 2010;9:174.

14. Kublin JG, Cortese JF, Njunju EM, Mukadam RAG, Wirima JJ, Kazembe PN, et al. Reemergence of chloroquine-sensitive Plasmodium falciparum malaria after cessation of chloroquine use in Malawi. J Infect Dis. 2003; 187:1870-5

15. Mohammed A, Ndaro A, Kalinga A, Manjurano A, Mosha JF, Mosha DF, et al. Trends in chloroquine resistance marker, Pfcrt-K76T mutation ten years after chloroquine withdrawal in Tanzania. Malar J. 2013;12:415.

16. Musyoka KB, Kiiru JN, Aluvaala E, Omondi P, Chege WK, Judah T, et al. Prevalence of mutations in Plasmodium falciparum genes associated with resistance to different antimalarial drugs in Nyando, Kisumu County in Kenya. Infect Genet Evol. 2020;78:104121.
17. Liu DQ, Liu RJ, Ren DX, Gao DQ, Zhang CY, Qui CP, et al. Changes in the resistance of Plasmodium falciparum to chloroquine in Hainan, China. Bull World Health Organ. 1995;73:483-6.

18. Sekihara M, Tachibana S-I, Yamauchi M, Yatsushiro S, Tiwara S, Fukuda N, et al. Lack of significant recovery of chloroquine sensitivity in Plasmodium falciparum parasites following discontinuance of chloroquine use in Papua New Guinea. Malar J. 2018;17:434

19. Wang X, Mu J, Li G, Chen P, Guo X, Fu L, et al. Decreased prevalence of the Plasmodium falciparum chloroquine resistance transporter 76T marker associated with cessation of chloroquine use against $P$. falciparum malaria in Hainan, People's Republic of China. Am J Trop Med Hyg. 2005;72:410-4.

20. Mbogo GW, Nankoberanyi S, Tukwasibwe S, Baliraine FN, Nsobya SL, Conrad MD, et al. Temporal changes in prevalence of molecular markers mediating antimalarial drug resistance in a high malaria transmission setting in Uganda. Am J Trop Med Hyg. 2014;91:54-61.

21. Apinjoh TO, Mugri RN, Miotto O, Chi HF, Tata RB, Anchang-Kimbi JK, et al. Molecular markers for artemisinin and partner drug resistance in natural Plasmodium falciparum populations following increased insecticide treated net coverage along the slope of mount Cameroon: cross-sectional study. Infect Dis Poverty. 2017;6:136.

22. Kiarie WC, Wangai L, Agola E, Kimani FT, Hungu C. Chloroquine sensitivity: diminished prevalence of chloroquine-resistant gene marker pfcrt-76 13 years after cessation of chloroquine use in Msambweni, Kenya. Malar J. 2015;14:328.

23. Ocan M, Akena D, Nsobya S, Kamya MR, Senono R, Kinengyere AA, et al. Persistence of chloroquine resistance alleles in malaria endemic countries: a systematic review of burden and risk factors. Malar J. 2019;18:76.

24. Rasmussen SA, Ceja FG, Conrad MD, Tumwebaze PK, Byaruhanga O, Katairo T, et al. Changing antimalarial drug sensitivities in Uganda. Antimicrob Agents Chemother. 2017;61:e01516-17.

25. Simon-Oke IA, Obimakinde ET, Afolabi OJ. Prevalence and distribution of malaria, Pfcrt and Pfmdr 1 genes in patients attending FUT Health Centre, Akure, Nigeria. Beni-Suef Univ. J Basic Appl Sci. 2018;7:98-103.

26. Tola M, Ajibola O, Idowu ET, Omidiji O, Awolola ST, Amambua-Ngwa A. Molecular detection of drug resistant polymorphisms in Plasmodium falciparum isolates from Southwest, Nigeria. BMC Res Notes. 2020;13:497.

27. Yobi DM, Kayiba NK, Mvumbi DM, Boreux R, Kabututu PZ, Situakibanza $H N T$, et al. Molecular surveillance of anti-malarial drug resistance in Democratic Republic of Congo: high variability of chloroquinoresistance and lack of amodiaquinoresistance. Malar J. 2020;19:121.

28. Asua V, Vinden J, Conrad MD, Legac J, Kigozi SP, Kamya MR, et al. Changing molecular markers of antimalarial drug sensitivity across Uganda. Antimicrob Agents Chemother. 2019;63:e01818-18.

29. Li B-S, Wang X-Y, Ma F-L, Jiang B, Song X-X, Xu A-G. Is high resolution melting analysis (HRMA) accurate for detection of human disease-associated mutations? A meta analysis. PLoS ONE. 2011;6:e28078.

30. Vossen RHAM, Aten E, Roos A, den Dunnen JT. High-resolution melting analysis (HRMA): more than just sequence variant screening. Hum Mutat. 2009;30:860-6.

31. Bentaleb EM, El Messaoudi MD, Abid M, Messaoudi M, Yetisen AK, Sefrioui $\mathrm{H}$, et al. Plasmid-based high-resolution melting analysis for accurate detection of rpoB mutations in Mycobacterium tuberculosis isolates from Moroccan patients. BMC Infect Dis. 2017;17:548.

32. Kassaza K, Operario DJ, Nyehangane D, Coffey KC, Namugosa M, Turkheimer $\mathrm{L}$, et al. Detection of Plasmodium species by high-resolution melt analysis of DNA from blood smears acquired in Southwestern Uganda. J Clin Microbiol. 2018:56:e01060-17.

33. Chen D, Wang Y-Y, Chuai Z-R, Huang J-F, Wang Y-X, Liu K, et al. Highresolution melting analysis for accurate detection of BRAF mutations: a systematic review and meta-analysis. Sci Rep. 2014;4:4168.

34. Daniels R, Ndiaye D, Wall M, McKinney J, Séne PD, Sabeti PC, et al. Rapid, field-deployable method for genotyping and discovery of single-nucleotide polymorphisms associated with drug resistance in Plasmodium falciparum. Antimicrob Agents Chemother. 2012;56:2976-86.

35. Ojuka P, Boum Y, Denoeud-Ndam L, Nabasumba C, Muller Y, Okia M, et al. Early biting and insecticide resistance in the malaria vector Anopheles might compromise the effectiveness of vector control intervention in Southwestern Uganda. Malar J. 2015;14:148.

36. Boyce RM, Muiru A, Reyes R, Ntaro M, Mulogo E, Matte M, et al. Impact of rapid diagnostic tests for the diagnosis and treatment of malaria at a 
peripheral health facility in Western Uganda: an interrupted time series analysis. Malar J. 2015;14:203.

37. Oyet C, Roh ME, Kiwanuka GN, Orikiriza P, Wade M, Parikh S, et al. Evaluation of the Deki Reader ${ }^{\mathrm{TM}}$, an automated RDT reader and data management device, in a household survey setting in low malaria endemic southwestern Uganda. Malar J. 2017;16:449.

38. De Beaudrap P, Nabasumba C, Grandesso F, Turyakira E, Schramm B, Boum $Y$, et al. Heterogeneous decrease in malaria prevalence in children over a six-year period in south-western Uganda. Malar J. 2011;10:132.

39. Roh ME, Oyet C, Orikiriza P, Wade M, Kiwanuka GN, Mwanga-Amumpaire J, et al. Asymptomatic Plasmodium infections in children in low malaria transmission setting, Southwestern Uganda. Emerg Infect Dis. 2016;22:1494-8.

40. Tumwebaze P, Tukwasibwe S, Taylor A, Conrad M, Ruhamyankaka E, Asua $V$, et al. Changing antimalarial drug resistance patterns identified by surveillance at three sites in Uganda. J Infect Dis. 2017;215:631-5.

41. Sanchez JA, Pierce KE, Rice JE, Wangh LJ. Linear-after-the-exponential (LATE)-PCR: an advanced method of asymmetric PCR and its uses in quantitative real-time analysis. Proc Natl Acad Sci USA. 2004;101:1933-8.

42. Andriantsoanirina $V$, Lascombes V, Ratsimbasoa A, Bouchier C, Hoffman J, Tichit M, et al. Rapid detection of point mutations in Plasmodium falciparum genes associated with antimalarial drugs resistance by using high-resolution melting analysis. J Microbiol Methods. 2009;78:165-70.

43. Gan LSH, Loh JP. Rapid identification of chloroquine and atovaquone drug resistance in Plasmodium falciparum using high-resolution melt polymerase chain reaction. Malar J. 2010;9:134.

44. Ikegbunam MN, Nkonganyi CN, Thomas BN, Esimone CO, Velavan TP, Ojurongbe $\mathrm{O}$. Analysis of Plasmodium falciparum pfcrt and pfmdr 1 genes in parasite isolates from asymptomatic individuals in Southeast Nigeria 11 years after withdrawal of chloroquine. Malar J. 2019;18:343.

45. Tumwebaze P, Conrad MD, Walakira A, LeClair N, Byaruhanga O, Nakazibwe $\mathrm{C}$, et al. Impact of antimalarial treatment and chemoprevention on the drug sensitivity of malaria parasites isolated from Ugandan Children. Antimicrob Agents Chemother. 2015;59:3018-30.

46. Pholwat S, Liu J, Stroup S, Jacob ST, Banura P, Moore CC, et al. The malaria TaqMan array card includes 87 assays for Plasmodium falciparum drug resistance, identification of species, and genotyping in a single reaction. Antimicrob Agents Chemother. 2017;61;e00110-17.

47. Murillo E, Muskus C, Agudelo LA, Vélez ID, Ruiz-Lopez F. A new high-resolution melting analysis for the detection and identification of Plasmodium in human and Anopheles vectors of malaria. Sci Rep. 2019;9:1674.
48. Yongkiettrakul S, Kampeera J, Chareanchim W, Rattanajak R, Pornthanakasem W, Kiatpathomchai W, et al. Simple detection of single nucleotide polymorphism in Plasmodium falciparum by SNP-LAMP assay combined with lateral flow dipstick. Parasitol Int. 2017;66:964-71.

49. Chahar M, Anvikar A, Valecha N. Development and evaluation of a novel HNB based isothermal amplification assay for fast detection of pyrimethamine resistance ( $\mathrm{S} 108 \mathrm{~N})$ in Plasmodium falciparum. Int J Environ Res Public Health. 2019;16:1635.

50. Chahar M, Mishra N, Anvikar A, Dixit R, Valecha N. Establishment and application of a novel isothermal amplification assay for rapid detection of chloroquine resistance (K76T) in Plasmodium falciparum. Sci Rep. 2017;7:41119.

51. Dondorp AM, Yeung S, White L, Nguon C, Day NPJ, Socheat D, et al. Artemisinin resistance: current status and scenarios for containment. Nat Rev Microbiol. 2010;8:272-80.

52. Mbengue A, Bhattacharjee S, Pandharkar T, Liu H, Estiu G, Stahelin RV, et al. A molecular mechanism of artemisinin resistance in Plasmodium falciparum malaria. Nature. 2015;520:683-7.

53. Straimer J, Gnädig NF, Witkowski B, Amaratunga C, Duru V, Ramadani AP, et al. Drug resistance. K13-propeller mutations confer artemisinin resistance in Plasmodium falciparum clinical isolates. Science. 2015;347:428-31.

54. Kamugisha E, Bujila I, Lahdo M, Pello-Esso S, Minde M, Kongola G, et al. Large differences in prevalence of Pfcrt and Pfmdr1 mutations between Mwanza, Tanzania and Iganga, Uganda-a reflection of differences in policies regarding withdrawal of chloroquine? Acta Trop. 2012;121:148-51.

55. Nsobya SL, Dokomajilar C, Joloba M, Dorsey G, Rosenthal PJ. Resistancemediating Plasmodium falciparum pfcrt and pfmdr1 alleles after treatment with artesunate-amodiaquine in Uganda. Antimicrob Agents Chemother. 2007:51:3023-5.

56. Zhou R, Zhang H, Yang C, Liu Y, Zhao Y, Li S, et al. Molecular mutation profile of pfcrt in Plasmodium falciparum isolates imported from Africa in Henan province. Malar J. 2016;15:265.

\section{Publisher's note}

Springer Nature remains neutral with regard to jurisdictional claims in published maps and institutional affiliations.
Ready to submit your research? Choose BMC and benefit from:

- fast, convenient online submission

- thorough peer review by experienced researchers in your field

- rapid publication on acceptance

- support for research data, including large and complex data types

- gold Open Access which fosters wider collaboration and increased citations

- maximum visibility for your research: over $100 \mathrm{M}$ website views per year

At BMC, research is always in progress.

Learn more biomedcentral.com/submissions 